Original Article

\title{
DENSITOMETRIC VALIDATION OF LAPACHOL IN TECOMELLA UNDULATA SEEM BARK BY HIGH-PERFORMANCE THIN-LAYER CHROMATOGRAPHY
}

\author{
RAJ RICHA ${ }^{1}$, SIDDIQUI NAHIDA, AERI VIDHU ${ }^{2 *}$ \\ Department of Pharmacognosy and Phytochemistry School of Pharmaceutical Education and Research, Jamia Hamdard, New Dehli \\ 110062 \\ Email: vidhuaeri@yahoo.com
}

Received: 20 Apr 2018 Revised and Accepted: 06 Jun 2018

\begin{abstract}
Objective: To develop a validated high-performance thin layer chromatography (HPTLC) method for the quantitative estimation of Lapachol in a Soxhlet extracted bark of Tecomella undulata seem (T. undulata).

Methods: The bark of T. undulata was extracted with chloroform by Soxhlet apparatus. The separation was achieved on a silica-gel $60 \mathrm{~F}_{254} \mathrm{HPTLC}$ plate using toluene-ethyl acetate-glacial acetic acid $(8.5: 1.5: 0.02 \mathrm{v} / \mathrm{v} / \mathrm{v})$ as a mobile phase. Densitometric analysis of Lapachol was carried out in absorbance mode at $254 \mathrm{~nm}$.

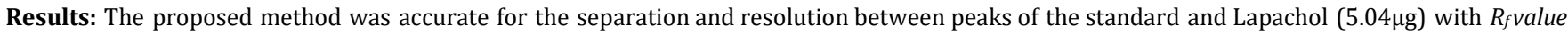
0.77 . Calibration curves were found to be linear over the concentration range $(10-130 \mu \mathrm{g})$ for Lapachol and correlation coefficient over $\left(\mathrm{R}^{2}=0.9973\right)$, indicating an excellent correlation between peak areas and concentrations of the marker compound. The experimentally derived LOD and LOQ for Lapachol were determined to be $0.028 \mu \mathrm{g}$ and $0.086 \mu \mathrm{g}$ respectively and the developed HPTLC-UV method showed lower \%RSD and SEM, value indicating the method to be precise, accurate and robust.
\end{abstract}

Conclusion: The study concludes that HPTLC-UV validation method can be very efficient and promising technique for the identification and quantitative analysis of Lapachol from T. undulata bark. The statistical analysis of data indicates that the developed method is reproducible and specific.

Keywords: Tecomella undulata, Lapachol, High-Performance Thin Layer Chromatography (HPTLC)

(C) 2018 The Authors. Published by Innovare Academic Sciences Pvt Ltd. This is an open access article under the CC BY license (http://creativecommons.org/licenses/by/4.0/) DOI: http://dx.doi.org/10.22159/ijpps.2018v10i7.26825

\section{INTRODUCTION}

Tecomella undulata Seem (Bigoniaceae) is a tree species, locally known as Rohida found in Thar Desert regions of India and Pakistan, which is used as a hepatoprotective agent in various ayurvedic formulations such as Rohitakarishta, Rohitakadyachurna, Rohitakaghrita and Rohitakalauha [1]. T. undulata bark consists of various chemical constituents which are primarily used in the treatment of syphilis, painful swellings and cancer. Lapachol (fig. 1) is a naturally occurring 1, 4-naphthoquinone originally isolated from Tabebuia avellanedae (Bignoniaceae) [2], used against, Trypanosome cruzi, cancer, viruses, bacteria, and Leishmania [3]. This constituent can also be found in other plant families such as, Verbenaceae, Leguminosae, Sapotaceae, Scrophulariaceae, Malvaceae and Proteaceae, however, its occurrence is higher in the Bignoniaceae family, particularly in the gender Tabebuia, along with other heterocyclic quinones [3]. Naphthoquinones are natural aromatic compounds that can be found in several plant families, as well as isolated from fungi, algae and bacteria. Traditionally used for their dyeing properties, however, recently a variety of biological activities of these compounds has been reported [3]. They are also categorized in a class of natural phenolic compounds formed on a C6-C4 skeleton. Due to its versatile pharmacological activity, it is isolated and analyzed from natural sources using a simple, efficient and reliable technique. Conventional Soxhlet extraction (CSE) has been used for a long time, especially because of its low cost and easy applicability as compared to the available novel techniques. Extraction of any kind of secondary metabolite by using a wide range of solvents is the added advantage of Soxhlet extraction [17]. Currently, HPTLC is often used as an alternative to HPLC for the quantification of plant products because of its simplicity, accuracy, cost-effectiveness and rapidity [17]. In this investigation, a validated high-performance thin layer chromatography (HPTLC) method was developed for the quantitative estimation of Lapachol in a Soxhlet extracted bark of (T. undulata).

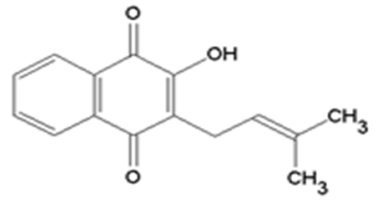

Fig. 1: Chemical structure of Lapachol

\section{MATERIALS AND METHODS}

\section{Chemicals and reagents}

Standard Lapachol were purchased from Sigma Aldrich fine chemicals, chloroform and methanol (HPLC grade) were used for the preparation of standard and sample and toluene: ethyl acetate-glacial acetic acid $(8.5: 1.5: 0.02 \mathrm{v} / \mathrm{v} / \mathrm{v})$ were used as a mobile phase for HPTLC analysis. All solutions used for analysis were filtered through a $0.1 \mu \mathrm{m}$ filter. Stem bark of T. undulata was collected from Lodhi Garden, New Delhi. The samples were authenticated by the National Institute of Science Communication and Information Resources (NISCAIR), New Delhi, India, reference no. NISCAIR/RHMD/Consult/2014/2472-51.

For HPTLC analysis of Lapachol, an HPTLC system from Chemie Erzeugnisse and Adsorptions Technik (CAMAG) AG (Muttenz, Switzerland) was used, equipped with a Linomat IV sample applicator. Lapachol extract was applied to aluminum, baked TLC plates $(20 \mathrm{X} 20 \mathrm{~cm})$ precoated with silica gel $60 \mathrm{~F}_{254}$ (Merck, Darmstadt, Germany). For developing TLC twin-trough CAMAG (vertical development) chamber was used.

\section{Extraction of plant material}

The plant material was collected from Lodhi Garden, New Delhi. Dried fine plant material was subjected to Soxhlet extraction with chloroform for $8 \mathrm{~h}$ at $37^{\circ} \mathrm{C}[11]$. 


\section{Preparation of standard}

$1 \mathrm{mg}$ compound was accurately weighed in an Eppendorf tube and mixed with methanol (HPLC grade). It was sonicated for 10 min and then filtered through $0.1 \mu \mathrm{m}$ filter.

\section{Sample preparation and application}

Accurately weighed $200 \mathrm{mg}$ of crude extract was dissolved in 50 $\mathrm{ml}$ of HPLC grade of chloroform and the solution was sonicated for $10 \mathrm{~min}$, and then made up with $10 \mathrm{ml}$ methanol before filtering through $0.1 \mu \mathrm{m}$ membrane syringe filter and injecting into the HPTLC system.

\section{Calibration curves for a standard solution}

A standard solution was applied in triplicate on silica gel $60 \mathrm{~F}_{254}$ plates, using CAMAG linomat-5 Automatic sample spotter. The plates were developed in toluene: ethyl acetate-glacial acetic acid (8.5:1.5: 0.02 $\mathrm{v} / \mathrm{v} / \mathrm{v})$ solvent in CAMAG glass twin-trough chamber $(20 \times 20 \mathrm{~cm})$ up to a distance of $8 \mathrm{~cm}$, after drying the HPTLC plates were scanned at 254 $\mathrm{nm}$, WINCATS software was used for recording and analyzing the chromatographic data.

The peak areas were recorded. Calibration curves of the Lapachol were obtained by plotting peak areas versus applied crude extract concentration of Lapachol.

\section{Assay validation}

The proposed HPTLC-UV method was validated as per the ICH guidelines [22].

\section{Calibration studies}

Linearity was evaluated in the range of $10-130 \mu \mathrm{g} / \mathrm{ml}$ for Lapachol. A peak area versus concentration was subjected to least square linear regression analysis and the slope-intercept and correlation coefficient for the calibration was determined.

Limit of detection (LOD) and limit of quantification (LOQ) was evaluated from the following expression:

$$
\begin{aligned}
& \mathrm{LOD}=3.3 \times \frac{\mathrm{SD}}{\alpha} \text { (slope of curve) } \\
& \mathrm{LQD}=10 \times \frac{\mathrm{SD}}{\alpha} \text { (slope of curve) }
\end{aligned}
$$

Where SD is the standard deviation and $\alpha$ is the slope of the curve.

\section{Accuracy studies}

The accuracy of the method was established by performing recovery experiments using the standard addition method at three different levels, the validity of the accuracy was calculated from the following equation:

$$
\left[\frac{\text { spiked concentration- mean concentration }}{\text { spiked concentration }}\right] \times 100
$$

\section{Precision studies}

The method was evaluated at inter and intra-day each level of precision was estimated by six sequential replicates of Lapachol at a concentration of 50 and $70 \mu \mathrm{g} / \mathrm{spot}$, the \% RSD and SEM of peak areas were calculated.

\section{Robustness}

For the determination of the robustness of the method, chromatographic parameters were intentionally altered by a small modification to determine their influence on the retention time and quantitative analysis.

\section{Specificity}

The specificity of the method was established by analyzing Lapachol standard and its presence in chloroform extract. The spot for Lapachol in the extract was confirmed by comparing the $R_{f}$ value, color and peak of the spot in samples with those of a standard.

\section{RESULTS}

\section{Method validation}

The proposed method was accurate for the separation and resolution between peaks of the standard and Lapachol with $R_{f}$ value 0.77 (fig. 1, fig. 2). Under described experimental conditions, the linear correlation between peak area and applied concentration was found in the concentration range of $10-130 \mu \mathrm{g} / \mathrm{ml}$ for Lapachol. The correlation coefficient for Lapachol was found to be 0.9973 , the regression equation calculated using $\mathrm{Y}=15.452 \mathrm{X}+310.23$. The experimentally derived LOD and LOQ for Lapachol were determined to be $0.028 \mu \mathrm{g}$ and $0.086 \mu$ g respectively (table 1 ).

\section{Precision}

Precision data repeatability inter-and intra-day for different concentration level are summarized in (table 2), the precision study showed RSD less than 1\%, indicating sufficient precision.

\section{Accuracy}

The satisfactory recoveries (table 3 ) indicate that the HPTLC-UV method is reliable for the quantification of Lapachol in chloroform extracts of $T$. undulata bark.

\section{Robustness}

Solvent system having a diverse composition of toluene-ethyl acetate-glacial acetic acid (8.5:1.5:0.02 $\mathrm{v} / \mathrm{v} / \mathrm{v}$ ) were tried at two different concentration levels of 50 and $70 \mu \mathrm{g} /$ spot and \%RSD of peak area were calculated (table 4).

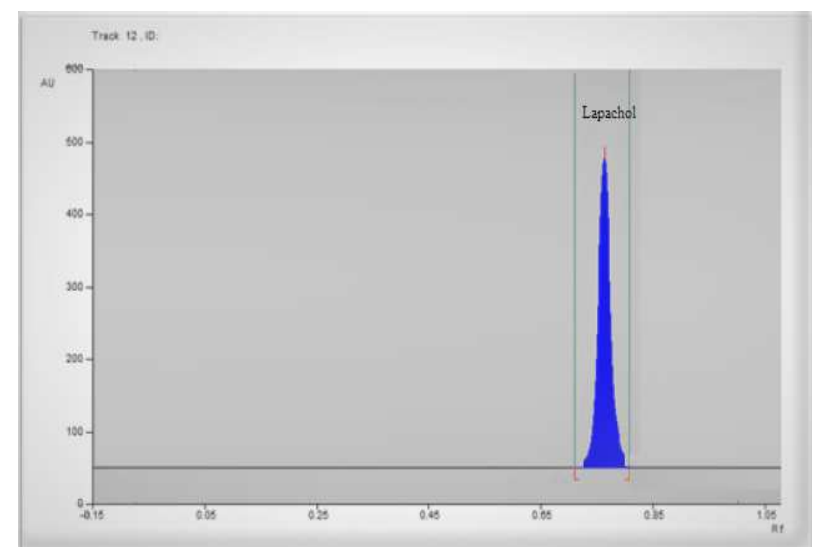

Fig. 2: HPTLC chromatogram of standard Lapachol

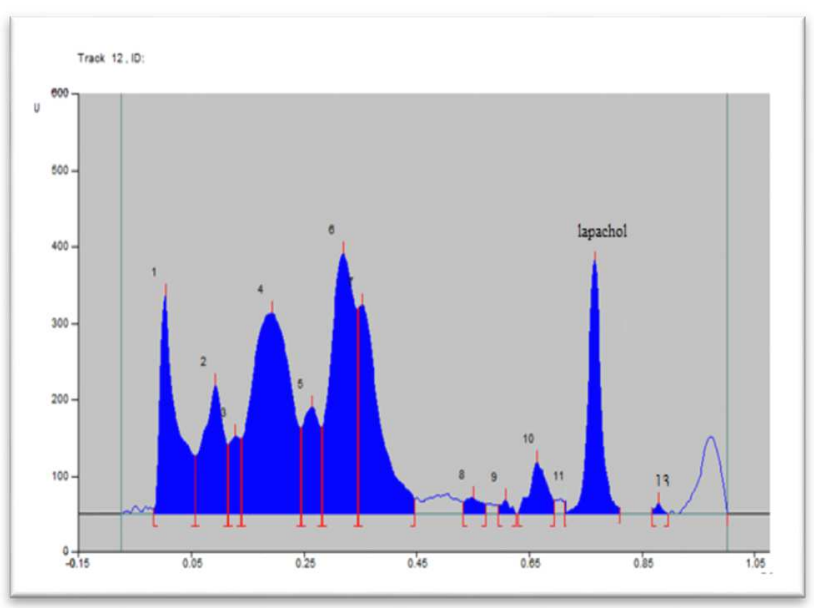

Fig. 3: HPTLC chromatogram of lapachol sample in $T$. Undulata extract 
Table 1: Densitometric validation summary of lapachol

\begin{tabular}{ll}
\hline Parameter & $10-130 \mu \mathrm{g}$ \\
\hline Linearity range & 0.9973 \\
Coefficient correlation & $\mathrm{Y}=15.452 \mathrm{X}+310.23$ \\
Regression equation (peak area) & $0.028(\mu \mathrm{g})$ \\
$\mathrm{LOD}(\mu \mathrm{g})$ & $0.086(\mu \mathrm{g})$ \\
$\mathrm{LQD}(\mu \mathrm{g})$ & 0.77 \\
$R f$ & $5.04(\mu \mathrm{g})$ \\
Lapachol content $(\mu \mathrm{g})$ & \\
\hline
\end{tabular}

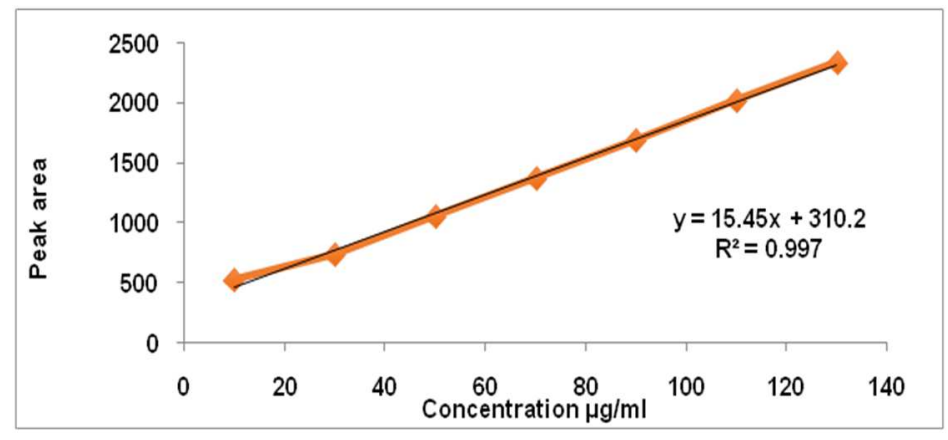

Fig. 4: Calibration curve for Lapachol

Table 2: Intra and inter day

\begin{tabular}{lllll}
\hline Amount on lapachol spot $(\boldsymbol{\mu g})$ & Mean & SD & \%RSD & SEM \\
\hline Intraday & & & & \\
50 & 1061 & 3.74 & 0.35 & 1.52 \\
70 & 1380.5 & 3.93 & 0.28 & 1.60 \\
Inter-day & & & & \\
50 & 1051 & 1.87 & 0.24 & 1.05 \\
70 & 1372.5 & 1.86 & 0.13 & 0.76 \\
\hline
\end{tabular}

Data represent mean $\pm \mathrm{SD}$ and mean $\pm \mathrm{SEM},(\mathrm{n}=6)$

Table 3: Accuracy analysis

\begin{tabular}{|c|c|c|c|c|}
\hline Amount of lapachol in sample $(\mu \mathrm{g})$ & $\%$ of standard lapachol in a sample & $\%$ recovery of lapachol (peak area) & \% RSD & SEM \\
\hline 5.04 & 10 & 527 & 0.15 & 0.46 \\
\hline 5.04 & 50 & 1055 & 0.14 & 0.88 \\
\hline 5.04 & 90 & 1690 & 0.11 & 1.16 \\
\hline 5.04 & 130 & 2341 & 0.03 & 0.50 \\
\hline
\end{tabular}

Data represent mean \pm SEM, $(n=3)$

Table 4: Robustness

\begin{tabular}{lll}
\hline $\begin{array}{l}\text { Lapchol } \\
(\boldsymbol{\mu g})\end{array}$ & $\begin{array}{l}\text { Toluene-ethyl acetate-glacial acetic acid }(8.2: 1.8: 0.02 \mathrm{v} / \mathrm{v} / \mathrm{v}) \\
\text { \%RSD via area }\end{array}$ & $\begin{array}{l}\text { Toluene-ethyl acetate-glacial acetic acid }(8.5: 1.5: 0.02 \mathrm{v} / \mathrm{v} / \mathrm{v}) \\
\text { \%RSD via area }\end{array}$ \\
\hline 50 & 0.95 & 0.15 \\
70 & 0.72 & 0.09 \\
\hline
\end{tabular}

Data represent mean $\pm \mathrm{SD}(\mathrm{n}=3)$

\section{DISCUSSION}

Development of new analytical methods for qualitative and quantitative estimation of active compounds in a crude plant extract is essential for pharmacokinetics, biological and toxicological studies and for standardizing them to maintain their quality and batch-tobatch reproducibility [18]. A simple, rapid and accurate method was developed for the first time for estimation of Lapachol from $T$. undulata bark by HPTLC. The standard compound was clearly resolved with sufficient resolution and no interfering peaks of endogenous compounds were observed. Calibration curves were found to be linear over the concentration range 10-130 $\mu \mathrm{g}$ for
Lapachol (table 1). The marker compound had a correlation coefficient $\left(R^{2}\right)$ value over 0.9973 , indicating that there was an excellent correlation between peak areas and concentrations of the marker compound. The specificity of the method was evidenced in the ( $R f$ ) results indicated that the developed method was selective and specific to distinguish and quantify Lapachol from a plant extract. Lowest LOD and LOQ values (table 1) of the standard indicated that the developed method was very sensitive and can be used for the detection and quantification of Lapachol over a wide range of concentration. Results of inter-and intra-day precession showed that $\%$ RSD value of peak area with high repeatability (table 2 ). There was not much variation in the inter-and intra-day precision, thus the 
method is extremely adaptable because of the good precision and excellent repeatability of the method. The results of inter-and intraday precisions of the present study were highly precise in comparison with the previously published analytical methods [19]. It was observed that the $R_{f}$, peak area and the recovery of the standard compounds were not significantly affected by small changes in the parameters as evident from the low values of \%RSD $(<2 \%)$ indicating the robustness of the method. This rapid and simple HPTLC-UV method was developed for the first time to determine the contents of Lapachol in the chloroform extract of $T$. undulata bark.

\section{CONCLUSION}

This study shows that an HPTLC-UV validation method can be very efficient and promising techniques for the identification and quantitative analysis of Lapachol from T. undulata bark. In this study, a solvent system was developed for the first time for the HPTLC-UV analysis of Lapachol. The solvent system was found good for resolution of Lapachol peaks. LOD and LOQ were found to be comparatively low which showed the greater sensitivity of the developed method. The statistical analysis of data indicates that the developed method is reproducible and specific.

\section{ACKNOWLEDGEMENT}

The authors are grateful to the Department of Pharmacognosy and Photochemistry, School of Pharmaceutical Education and Research (SPER), Jamia Hamdard, New Delhi.

\section{AUTHORS CONTRIBUTIONS}

Richa Raj, designed, carried out and wrote up the research article, Vidhu Aeri, supervised and helped in designing the work, Nahida Siddiqui guided and proofread the research article.

\section{CONFLICTS OF INTERESTS}

The authors declare no conflict of interest

\section{REFERENCES}

1. Jain M. Hepatoprotective potential of Tecomellaundulata. J Ethanol 2012;1:194-200.

2. LM Viana, MR Freitas, SV Rodrigues, W Baumann. Extraction of lapachol from Tabebuiaavellanedae wood with supercritical $\mathrm{CO}_{2}$ : an alternative to soxhlet extraction. Braz J Chem Eng 2003;3:317-25.

3. Sudha T, Hemalatha PV, Ravikumar VR, Jothi R, Radhakrishnan M. Development and validation of RP-HPLC method for the estimation of rifaximin in bulk and in tablet dosage form. Asian J Pharm Clin Res 2009;4:112-6.

4. Pundir S, Tomar SK, Mishra SH. Pharmacognostical standardization and chromatographic evaluation of Tecomellaundulata stem, bark. Int J Biol 2015;4:4499-508.

5. Khan MA, Shah AH, Khan SB. Study of Tecomellaundulata g. Don. methanolic extract against Sarcoptesscabiei Lin vivo and in vitro. J Animal Plants Sci 2013;23 (1 Suppl):47-53.

6. Neeraj V, Sangita P. A validated HPTLC method for simultaneous estimation of nebivolol and indapamide in the solid dosage form. Asian J Pharm Clin Res 2012;4 Suppl 4:1-4.
7. Srivastava S, Choudhary GP. Phytochemistry and pharmacological activity of Tecomellaundulata, mintage. J Pharm Med Sci 2014;3 Suppl 3:27-30.

8. Malikka A, Ravi A, Sama V, Khan RS. Antiproliferative activity and standardization of Tecomellaundulataextract on K562 cells. J Ethanol 2011;3:1353-9.

9. Ramkumar K, Sharma S, Kumar Suresh. An overview for various aspects of multifaceted, health care Tecomellaundulata seem. Plant Acta Poloniae Pharm Drug Res 2010;5:993-6.

10. Delma D, Anu B, Eena J, Aneesh TP. Bioanalytical method development and validation of Ticagrelorby RP-HPLC. Int J Appl Pharm 2017;3:51-4.

11. Sayyadnia N. Measurement of lapachol by HPLC in Iranian Tecomellaundulata (Roxb). Seem. Med Aromatic Plant Sci Biotech 2010;1:59-61.

12. Prema SK. HPTLC and GC MS analysis of bark of Stereospermumscolais. Int J Sci Res 2015;8:1-11.

13. Baskarananda Raj V, Suresh S, Senthil KL. HPTLC standardization and quantification of Rhinacanthusnasutu. J Plant Stud 2015;2:51-5.

14. UK Katare DP, Aeri V. Densitometric validation and optimization of polyphenols in ocimum sanctum linn by HPTLC. Phytochem Anal 2015;26:237-46.

15. Hidayat Hussain. Lapachol: an overview. ARKIVOC. $2^{\text {nd }} e d n$ : Gaines Ville FL US; 2007. p. 145-71.

16. Navneet N. Quantitative estimation of tecomin in Tecomellaundulata bark using HPTLC method. J Biomed Pharm Res 2013;7:19-23.

17. Nahida S, Vidhu A. Optimization of betulinic acid extraction from Tecomellaundulata bark using a box-behnken design and its densitometric validation. Molecules 2016;1-12. Doi:10.3390/molecules21040393

18. Shrikumar S. HPTLC method for standardization of Curculigo orchioids rhizomes and its marketed formulation using Gallic as standard. Indian J Pharm Sci 2005;67:721-4.

19. J Sherna. Encyclopedia of pharmaceutical technology. $2^{\text {ndedn: }}$ 2001. p. 252-4.

20. Pandit S, Kumar M, Ponnusankar S, Pal BC, Mukherjee PK. RPHPLCDAD for simultaneous estimation of mahanine and mahanimbine in Murrayakoenigii. Biomed Chromatogr 2011;25:959-62.

21. Shailajan S, Menon S, Sayed N, Tiwari B. Simultaneous estimation of three triterpenoids from Carissa carandas using validated high-performance liquid chromatography. Int J Green Pharm 2012;6:241-7.

22. ICH/CPMP guidelines Q2B, validation of analytical procedures; 1994.

23. Wang L, Weller CL. Recent advances in extraction of Nutraceuticals from plants trends. Food Sci Technol 2006;17:300-12.

24. E. Haftmen. Chromatography fundamentals and applications of chromatography and related differential migration methods. Elsevier; 2004. p. 253-91.

25. British Pharmacopoeia. International edn. HMSO, Cambridge, Appendix 112 (IB); 2002.

26. J Cazes, RPW Scott. Chromatography Theory, Marcel Decker, New York; 2002. p. 443-54.

27. PD Sethi. HPTLC: quantitative analysis of pharmaceutical formulations. CBS Publications; 1996. p. 162-5. 